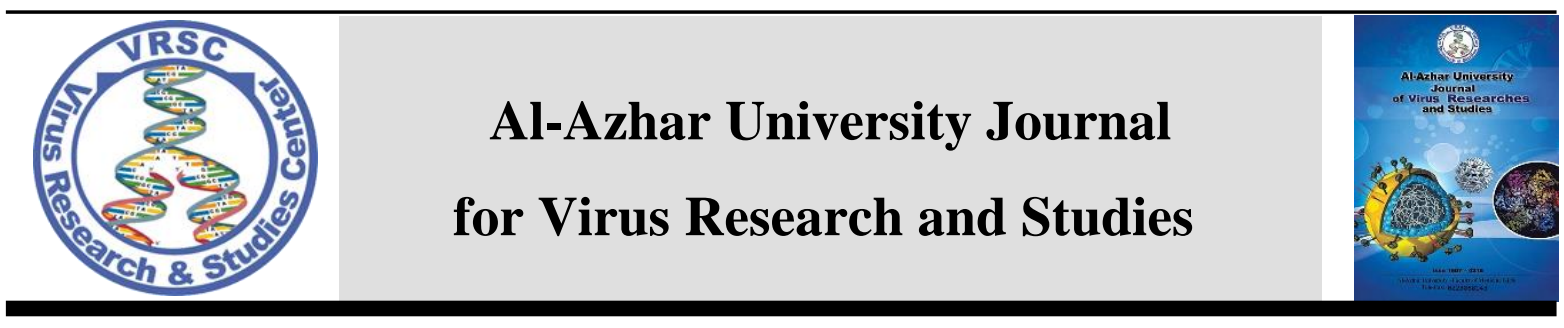

\title{
Garlic and It's Anticancer Activity
}

\author{
Laila M Aboughazala, Amira M. Shaban * \\ Center for Virus Research and Studies, Al-Azhar University, Cairo, Egypt \\ *E-mail: vrsc@azhar.edu.eg
}

\begin{abstract}
Shaped plants, which additionally contain onions, scallions, leeks, and chives. Garlic is utilized for its flavoring in cooking and is exclusive because of its sulfur content material. Garlic also incorporates arginine, oligosaccharides, flavonoids, and selenium all of which may be recommended to health . Garlic has plenty of Benefits results because it is helping to control: Blood sugar, high LDL cholesterol, chemo-preventive effects, anti-fungal, antibacterial, antiparasites . Garlic has numerous antitumor results including tumor cell enlargement inhibition, inhibit the advance of chemically prompted tumors, block covalent binding of cancer agents to DNA, make stronger degradation of cancer agents, have anti-oxidative and free radical scavenging houses, and control cell proliferation, apoptosis, and immune responses.
\end{abstract}

Keywords: Organosulfur compounds, Diallyl trisulfide, Tumor suppressor gene, Programmed cell death.

\section{Introduction}

Tumor is a large problem going through our world, the incidence of tumor in 2030 is anticipated to increase to 22.2 million instances [1]. It accounts for 1.68 tumor cases within the United States throughout 2017, which might result in the loss of life of 600,920 incident people [2]. Tumor does not differentiate between races and ages [3]. Medicinal drugs from herbal are favorable than other artificial due to their low-price, easy to find, and health-promoting characters. These health-promoting characters found in crops are because of phytochemicals which are the biologically essential chemical molecules that can be mainly all for modulation of quite a lot of metabolic pathways, like free radical scavenging, antimicrobial properties, and protecting sicknesses .[4] Garlic was once discovered to be a very powerful function as a healthy-based daily diet. The medicinal uses of various herbs have been proven experimentally as lifesaving entities, associated with well-being claims owing to their wealthy phytochemicals profile [5]. Plants of the family Allium together with garlic and onions have long been identified to have medicinal houses [6]. Research have proven that Organosulfur compounds (OSC) [7] are the principal bioactive brokers answerable for the noticed beneficial effects. Diallyl trisulfide [8], a bioactive OSC present in garlic, is reported to modulate illness states akin to a tumor, infection, and metabolic syndrome [9]. Health-promoting facets of garlic are principally accepted to its sulfur-containing compounds allicin and S-allyl cysteine[10] 
Among organosulfur compounds, thiosulfinates, ajoenes, and allicin (diallyl thiosulphate) are the manager bioactive elements in garlic chargeable for curing various illnesses [11].

\section{Garlic History:}

Recent research investigated new sources of chemotherapeutics that are healthy for human illnesses [12]. These agents' paintings in a way similar to the normal therapeutic compounds present in garlic, an element of the Allium sorts, were neatly recorded during the historical past [13]. Specifically, large-scale epidemiological research within the past few decades have suggested a correlation between garlic usage and a knock off the incidence of tumor [14].

For a long time of years, man has used herbal, animals, vegetation, and microbial products either within the natural form or crude extracts to treat many illnesses [11]. Garlic is a type of crop that was seriously researched over hundreds of years and deal with infectious sicknesses [15]. Garlic is known in several names comparable to maidenhair tree, stinking rose, Allium sativum, rustic treacle, the nectar of the Gods poor guy's treacle, and camphor of the deficient [16]. Garlic has been grown from Central Asia for over 6,000 years in the past however has distributed all over the place a long time ago. It is a relative of the red onion and leek, and other similar species having the aromatic sulfur-based substances, which contribute to the standard scent and taste, in addition to garlic's really useful healing results [17].

Garlic is a public meal for taste and spice and has been traditionally well-liked by strong folkloric awareness. The uptake of garlic as meals and remedies dates to ancient times. Garlic was applied as a cleaner for injuries all over World War II since penicillin and sulfa medicine was scarce. Many advisable experimental and clinical results of the consumption of garlic preparations, together with garlic extract, have been reported. Even these days the medicinal use of garlic is common and rising [18].

Modern clinical research advised strong correlations between garlic intaking as a nutritional supplement or food and several health advantages. It is the most important plant, which has various helpful results. Different research has assured that the chemo-preventive process of garlic through the use of different garlic cloves arrangements together with recent garlic extract, aged garlic, garlic oil, and several other organosulfur substances take from garlic. Fresh and grounded garlic has been played to reduce malignancy growth [19]. For three thousand years Garlic has been used in medications and foodstuff as evidenced through historic writings from China, Egypt, Greece, and India [20]. Epidemiological studies have presented that the increase in nutritional intake of garlic may reduce the incidence of more than one type of tumor $[21,22]$. Other beneficial results include antiatherosclerosis [23], blood lipids and sugar modulation [24], antifungal [25], antimicrobial [26], antithrombotic [27], cardiovascular disease treatment [28], stimulating immune system [29], bactericidal [30] and antibiotic [31] characters.

\section{Garlic classification:}

Allium sativum (garlic) is an element of the Liliaceae family, which also contain onions, chives, scallions, or leeks. Garlic contains a high amount of sulfur compounds, which give its characteristic taste, odor, and beneficial well-being results [32]. The most up-to-date 
classification of garlic according to nuclear ribosomal DNA [33].

Table 1.Garlic classification

\begin{tabular}{|c|c|}
\hline Class & Liliopsida \\
\hline Subclass & Liliidae \\
\hline Superorder & Liliianae \\
\hline Order & Amary-llidales \\
\hline Family & Alliaceae \\
\hline Subfamily & Allioideae \\
\hline Tribe & Allieae \\
\hline Genus & Allium \\
\hline
\end{tabular}

\section{Garlic chemical composition:}

Funder and Blackwood say that 3 and 6 gram of garlic clove contains about $1 \mathrm{~g}$ of carbohydrates, $0.2 \mathrm{~g}$ of protein, $0.05 \mathrm{~g}$ of fiber, $0.01 \mathrm{~g}$ of fat and vitamins $\mathrm{A}, \mathrm{B} 1, \mathrm{~B} 2$, B3, and C. Vitamin B1 (thiamin) is bound to allicin molecule and is known as allithiamine and is easily absorbed into the gut [34]. Garlic can decrease blood sugar levels [35]. Fulder and Blackwood [34] reported that garlic is abundant with adenosine, a nucleic acid that is a structure block of DNA and RNA. The main antiplatelet compound originated in garlic known to be adenosine [36].

Generally, garlic bulb rich in $65 \%$ water, $28 \%$ carbohydrates (mainly fructose), $2.3 \%$ organosulfur compounds, $2 \%$ protein (mainly alliin), $1.5 \%$ fiber, and $1.2 \%$ free amino acids (main arginine) [37]. Garlic has about 33 sulfur compounds (alliin, allicin, ajoene, allyl propyl disulfide, diallyl trisulfide, S-allyl cysteine, vinyl dithiins, Sallylmercaptocystein, and others), several enzymes (myrosinase, peroxidases, allinase, and others), minerals (germanium, selenium, tellurium, and other trace minerals) and 17 amino acids (arginine and others) [37].

Sulfur compounds can be broadly assorted as oil-soluble and water-soluble substances. During the cycle of garlic aging, lipidsoluble substances are naturally modified into more constant and bioavailable watersoluble compounds. Oil-soluble substances include diallyl sulfide, diallyl trisulfide, and diallyl disulfide, allyl methyl trisulfide, dithiins, and ajoene. The most important primary sulfur compound appearing in the intact garlic bulbs is alliin ( $\mathrm{S}$-allyl cysteine sulfoxide). Biological action of garlic is related to its special organosulfur compounds [38].

Alliin is a non-protein amino acid and has four stereoisomers but only one isomer is found in garlic. Dried out, powdered garlic has around $1 \%$ alliin (S-allyl cysteine sulfoxide). Corresponding to two studies of garlic clove preparations, allicin reduced to non-detectable quantities within $1-6$ days [39].

Allicin (diallyl thiosulphate) chemically known as 2-propene-1-sulfinothioc acid S2-propenyl ester; thio-2-propene-1-sulfinic acid S-allyl ester [40] and found out by [30] in 1944, responsible for garlic's smell. Allicin will not exist in garlic clove until it is smashed or cut; injury to the garlic bulb activates the enzyme alliinase [41], which metabolizes alliin to allicin [42]. Allicin can simply diffuse into the vesicles or into the cytoplasm of red blood cells. Lipid bilayers do not form an obstruction for allicin breakthrough and its circulation via the lipid bilayer and it does not form membrane aggregation, fusion, or leakage [43]. allicin can permeate very quickly into different parts of the cells and do its biological action. Thus, the need for allicin as a biological effectors' compound is due not only to its high reactivity with different 
molecular weight thiols and its antioxidant activity [44] but also due to its availability caused by high membrane permeability. Because of its high reactivity, allicin was appeared to be metabolized in the liver [45]. Unlike oily sulfur substances, watersoluble compounds are odorless and have a more delicate and less special flavor [46]. These substances are also created during aqueous garlic extraction when the primary compound $\gamma$-glutamyl-S-allyl cysteine is turned into $\mathrm{S}$-allyl cysteine and this reaction is catalyzed by $\gamma$-glutamyl transpeptidase $(\gamma$ GT). S-allyl cysteine and its derivatives, S-methyl cysteine and S-allyl cysteine are substances of aqueous extracts of garlic and have biological activity both in vitro and in vivo [47].

\section{Antitumor Activity of garlic compounds:}

\section{1- Induction of apoptosis through Caspase activation}

In such condition's garlic-derived substances especially sulfur compounds, saponins, and vitamins can evoke a tumor suppressor gene and prevent the transformation of proto-oncogenes directly into oncogenes. All this can be achieved because of genetic rearrangements of protooncogenes and mutations. the transformation of proto-oncogenes into oncogenes needs mutation that would lead to the formation of qualitatively various gene products that may harm the normal physiological metabolism of a natural cell [48]. Moreover, garlic components modulate the amount of Bax, Bcl-2, Bcl$\mathrm{xL}$, and Bcl-in a dose-dependent manner, and stimulate apoptosis in the MCF-7 breast-tumor cell line via interfering with cell-cycle growth phases in a manner that elevates the sub-G(0) population and significantly halts DNA synthesis [48]. Garlic increase caspase action which stops or stalls mutation in the p53 gene (tumor suppressor gene) and thereby prevent the formation of lung, breast, and colon tumor. Garlic components work upon two paths of target cell apoptosis activated via CTLs and via Fas route in which ligation of trimeric Fas systems by CTL bore Fas ligands contribute to connecting the death domains of Fas with FADD. These substances regulate some reactions which could result in apoptosis of the target cell. Garlic substances may stimulate CTL functions and stimulate the caspase cascade that results in the apoptotic death of the cellular death by invoking mitochondrially mediated death route. DATS- promote apoptosis and decrease of Bcl-2, cyclin D1, and Akt protein levels, and increase of Bax, p53, Fas, and cyclin B protein levels in Capan-2 cells [49].

\section{2- Induction of Apoptosis-related Proteins}

Few vital derivatives from garlic which includes ajoene, allicin, DADS, DAS, DATS, and SAMC, have been observed to stimulate apoptosis and cell cycle arrest in numerous cancer cell lines grown in culture. There are numerous more selections that distinctive natural products may select a different pathway to hold up apoptosis in cancer cells. Depending on the chosen agent and the concentrations used, apoptotic action can be recognized between 8-72 h post-treatment. Also, garlic oil promotes programmed cell death, cell cycle arrest, and display pro-apoptosis effects in AsPC-1cells and human pancreatic carcinoma cells [50].

S-allylcysteine is an important restorative compound extracted from garlic derivative that suppresses proliferation and promotes apoptosis in human ovarian tumor cells in vitro [51], also used to enhance apoptosis in oral tumor and breast cancer cells via ROSmediated activation of JNK [52]. Allicin, 
common garlic constituents, prevents cell development and promotes apoptosis in U87MG human glioblastoma cells through an ERK-dependent pathway [53]. It induces p53-mediated autophagy in HepG2 human liver tumor cells $[54,55]$ and stimulates apoptosis in EL-4 cells in vitro via activation of the appearance caspase- 3 and -12 and increase the ratio of $\mathrm{Bax} / \mathrm{Bcl}-2$ [56]. Further, it stimulates apoptosis in gastric malignancy cells via activation of both extrinsic and intrinsic routes [57].

Furthermore, Allicin stimulates autophagic cell death in human HCC HepG2 (p53 wildtype) cells, it may additionally induce apoptotic cell death by caspase-dependent and caspase-independent routes by overproduction of reactive oxygen species (ROS) in human HCC Hep3B (p53 (mutation)) cells. Moreover, Allicin treatment stimulates apoptotic cell death in p53 decrease HepG2 cells much like that of Hep 3B cells [54].

Diallylpolysulfides increase cell arrest and apoptosis in cancer cells [58]. Allyl sulfides stop cell development of skin cancer cells through stimulation of DNA destruction mediated G2/M arrest and apoptosis [56]. Diallyl tetrasulfide stimulates mitotic arrest to apoptosis [59]. Also, it stimulates apoptosis in human primary colorectal cancer cells [60] and AGS gastric tumor cell line [61]. Diallyl trisulfide [49] and Salkenyl mercapto cysteine (CySSR) with sodium selenite promotes apoptosis in pancreatic cells [62]. In an equal way, diallyl disulfide plays a vital function in NF$\kappa \mathrm{B}$ mediated transient G2-M phase arrest and apoptosis in human leukemic cell-lines [63].

DATS- prompted apoptosis is associated with the production of pro-apoptotic Bax protein and $\mathrm{p} 53$ protein presence that became observed up-regulated and translocation to the nucleus in MCF-7 cells [64]. DATS modulate $\mathrm{Bcl}-2$ family proteins, leading to improved apoptosis of
T24 cells [56]. This is the possible mechanism by which allyl sulfides inhibit neoplastic cell development [65]. S-benzylcysteine go between cell cycle arrest and apoptosis which including activation of mitochondrial-dependent caspase cascade via the p53 path in human SGC-7901 cells [66].

\section{3- Cell Cycle Checks-points:}

During the G1 stage, the cancer suppressor $\mathrm{Rb}$ binds and suppresses transcription factor E2F. More specifically, diallyl trisulfide- promote $\mathrm{G} 2 / \mathrm{M}$ phase cell cycle arrest in DU145 cells is released with late nuclear translocation of cyclin-dependent kinase 1 [63, 67]

DAS additionally promote G0/G1 cell cycle arrest [68] and apoptosis in HeLa cells via a caspase- and mitochondria and p53 pathways. It significantly prevents the development and promotes apoptosis of human cervical tumor HeLa cells in vitro [69].

DAS- enhanced G0/G1 phase arrest is mediated through the elevated expression of p27, p21, and p53 with a simultaneous decrease in CDK6, CDK2, and CHK2 expression. DAS exposed Ca Ski cells undergo apoptosis, with huge morphological modifications and DNA condensation. It causes changes in the ratio of $\mathrm{Bax} / \mathrm{Bcl}-2$, and increases mitochondrial disorders, which affects the launch of cytochrome $\mathrm{c}$ for the lead to apoptosis in $\mathrm{Ca}$ Ski cells. Because of these properties, DAS is considered as a chemotherapeutic factor for the drug of cervical tumor [70]. SAllylmercaptocysteine does cell cycle arrest at the G2/M and sub-G1 interphases [62].

\section{4- Control of DNA Damage:}

Several extracellular factors like ionizing radiation, Ultraviolet light, environ-mental 
chemicals, and alkylating agents lead to DNA harm in cells that subsequently result in carcinogenesis. Many potential treatments are getting used to focusing on cancer-causing agents via a sequence of alternatives including plantderived pharmaceutical agents. Massive quantities of those natural treatments arise from garlic and are getting used to treat tumor individuals especially for the prevention of tumor cell development and growth.

DNA lesion led to an impaired cellular response because of hyper-sensitivity generated from carcinogenic agents. If this DNA harm stays defective for a long time it causes mutations that result in altered protein activity and generate impaired cellular responses. Regular cells react to DNA harm by stalling progress via the cell cycle at a checkpoint till the damage has been repaired or triggering apoptosis if the harm stays un-reparable. All this is initiated with the aid of ATM protein briefly which senses DNA harm and relays the signal to the $\mathrm{p} 53$ protein that's synthesized under the regulation of p53 gene that is called the guardian of the genome [71].

Garlic shows potentially useful outcomes in tumor development and ameliorates chemotherapy prompted toxicities [72]. However, endogenous mechanisms lead to DNA harm like spontaneous chemical hydrolysis, intracellular interaction with reactive oxygen groups, and mistakes in replication and recombination can be restored through identifying correct and suitable biomolecules from garlic in form of a formulation. Further, a chemical carcinogen caused modifications like depurination, deamination, and reactive oxygen species which including superoxide anion formation managed through especially permeable oxygen-bearing molecules from garlic. Diallyl sulfide (DAS), one of the important active substances of garlic, leads to growth suppression of tumor cells in vitro and promotes immune responses in vivo [69].

Moreover, garlic-based drugs or unpurified extracts from green garlic cloves to promote apoptosis via the formation of reactive oxygen species in Hep3B cells [73]. Those additionally target DNA restore mechanisms and do recovery of a chain of metabolic and signaling pathways. [74].

The drug might also goal effectively on the right timing of cellular activities that may prevent cell cycle or delay it. Thus, the passage of anticarcinogenic impact via a checkpoint from one cell cycle phase can even require a coordinated set of proteins that monitor cell development and DNA integrity.

The usage of herbal products /molecules in a state of deficiency of transcription and translation of cell cycle proteins may promote DNA synthesis and protein translation. Garlic, one of these substances that can prevent out of control cell division or propagation of harmed DNA and keep cells from genomic instability that offers rise tumorigenesis.

Diallyl trisulfide does transcriptional repression and supression of nuclear translocation of the androgen receptor in human prostate tumor cells [75]. It additionally inhibits estrogen receptor- $\alpha$ activity in human breast tumor cells [76]. Thus garlic-based natural drugs have proven potential useful effects on tumor development and may ameliorate chemotherapy-promoted toxicities.

SAllylmercaptocysteine SAMC from garlic elevates p53, Bax, and Bad ratio which suggests that apoptosis happens through the mitochondrial pathway [62].

DADS induces apoptosis within the MCF7 breast-tumor cell line thru interfering with cell-cycle growth phases in a manner that raises the sub-G(0) population and substantially halts DNA synthesis [77]. It additionally induces phosphatidylserine translocation from the internal to the 
external of the plasma membrane and turns on caspase-3 [77]. It also modulates the cellular levels of Bax, Bcl-2, Bcl-xL, and $\mathrm{Bcl}-\mathrm{w}$ in a dose- based manner and display the involvement of Bcl-2 member proteins in apoptosis [77].

Diallyl trisulfide (DATS) stimulates apoptosis and prevents the development of many tumor cell lines. Especially it stimulates apoptotic cell death in human primary colorectal tumor cells via a mitochondrial-dependent caspase cascade signaling pathway via a significant reduction of the anti-apoptotic Bcl-2 that leads to increasing of the ratio of $\mathrm{Bax} / \mathrm{Bcl}-$ 2 and the activity of caspase- $3,-8$, and -9 [61, 78]. It additionally elevates within the ranges of cytochrome $c$ and caspase- 3 and caspase- 9 activity [61].

In the end, DATS support the apoptosis and stop the tumor cell growth in a concentration- and time-dependent manner [78]. DATS also spend chemo-preventive potential via ER stress and the mitochondrial passage in BCC cells [79]. DAS, DATS, and DADS obstructed COX2 and NF- $\kappa$ B for causing the suppression of cell growth [80].

Further, allicin additionally prevents the cell growth of U87MG human glioma cells in a dose- and time-dependent manner. Allicin-induced prevention of cell viability as a result of apoptosis of cells. The system of apoptosis had been to include the mitochondrial passage of $\mathrm{Bcl}-2 / \mathrm{Bax}$ and antioxidant enzyme systems [53].

Also, both diallyl tri- and tetrasulfide are indicated as strong inducers of a prior mitotic arrest and later apoptosis [59]. Diallyl tetrasulfide works independently of reactive oxygen species and tubulin represents one of its principal cellular objectives. Tubulin depolymerization blocks the creation of ordinary spindle microtubules, thereby cause a G2/M arrest. Moreover, c-jun N-terminal kinase, which stimulates early in reply to diallyl tetrasulfide treatment, intermediate multisite phosphorylation, and following proteolysis of the anti-apoptotic protein Bcell lymphoma 2 [59].

Similarly, both SFN Sulforaphane (SFN) and NaHS activate p38 mitogen-activated protein kinases (MAPK) and c-Jun Nterminal kinase (JNK) [81]. Thus, pretreatment of PC-3 cells with methemoglobin lowering SFN-stimulated MAPK action. Suppression of each JNK and p38 MAPK reversed H(2)S- or SFNdecreased growth of PC-3 cells. H(2)S go between the inhibitory effect of SFN on the growth of PC-3 cells. Consequently, H(2)Sliberating diet or drug is probably useful inside the remedy of prostate tumor [81]. Further, phytoalexins display unique objectives in tumor cells that consist of signal transduction pathways, cell cycle checkpoints, nuclear receptors, intrinsic and extrinsic apoptotic paths, matrix metalloproteinase and cell invasion, transcription factors, and the phase II detoxification path. Thiacremonone inhibits cancer development accompanied by the decrease of glutathione peroxidase activity, but it shows an elevate in the aspect of cleaved caspase 3, -8, -9, Bax, p21 and p53) [82]. Garlic extract increases cytotoxic and apoptotic activity in HL-60 cells that are mediated using oxidative stress [83], phosphatidylserine externalization, nucleosomal DNA fragmentation and the formation of MDA and caspase- 3 activation, a by-product of a biomarker of lipid peroxidation and oxidative stress[83].

\section{Role of Linoleic acid and conjugated linoleic acid found in garlic:}

\section{1-Linoleic acid (LA):}

Even though all the $\boldsymbol{\omega}-6 \mathrm{~s}$ can directly immediately eat up the daily food, LA, the 
precursor of $\boldsymbol{\omega}-6 \mathrm{~s}$, is more abundant in plant seeds and oils, and as a result, is taken into consideration to be the principal dietary supply of all $\omega-6 \mathrm{~s}$. Research evidence indicates that LA can be concerned in both pro and anti-tumor activities.

As an example, LA stimulates cell proliferation within the human breast tumor cell line BT-474 and the human lung tumor cell line A549 in vitro and promotes colon and prostate tumorigenesis and tumor growth in animal models [84, 85]. Alternatively, an excessive dose of LA decreases the proliferation of the colon tumor cell line Caco-2 [86], while an excessive intake of LA also shows a protecting impact on tumor improvement [87].

\section{2-Conjugated linoleic acids (CLAs):}

Conjugated linoleic acids (CLAs) are a sequence of isomers of LA (mainly cis-9, trans-11 and trans-10, cis-12) with conjugated double bonds in their structures. Although chemically not associated to the w-6 family, CLAs can be produced from the endogenous biohydrogenation of LA via gastrointestinal tract bacteria [88, 89]. CLAs were extensively studied and proven to have anti-tumor effects in several tumor sorts both in vitro and in vivo.

For example, in vitro research confirmed that CLA isomers ought to inhibit cell development in diverse tumor cell lines contain breast tumor cell line MCF-7 [90, 91], colon tumor cell lines HT-29, DLD-1, and Caco-2 [92, 93], the prostate tumor cell lines PC-3 [91, 94, 95] and the gastric tumor cell line SGC-7901[96].

\section{3- $\gamma$-Linolenic acid:}

Evidence indicates that GLA is also related to anti-tumor activities both in vitro and in vivo. As an example, GLA decrease cell development of cell lines GOTO, NKP, SK-N-DZ, and NCG, the rat carcinosarcoma cell line LLC-WRC256 , and a rat C6 glioma cell line in vitro [97, 98]. A nutritional complement of GLA additionally decreased cancer development in an implanted WRC256 rat model [99].

Extra interestingly, GLA- stimulate cytotoxicity was proven to exhibit excessive selectivity towards tumor cells without significant impact on regular cell growth. For example, the sequence of research recommended that 37 days of incubation with GLA could selectively stimulate cell death in numerous human tumor cell lines, which including the human breast tumor cell ZR-75-1, the lung tumor cell A549, and the prostatic tumor cell PC-3, without affecting regular cell development [100, 101].

GLA was proven to inhibit the growth of malignant rat astrocytoma cell line $36 \mathrm{~B} 10$ without affecting normal astrocytes. GLA additionally improved the radiation sensitivity of astrocytoma cells, but not regular astrocytes [102]. In the in vivo C6 glioma rat model, the infusion of GLA was proven to enhance the frequency of cell apoptosis and regression in cancers, without influencing regular neural tissue and vasculature [97]. Consequently, GLA appears to be a promising tumor therapeutic agent with perfect characteristics, although the reason for the excessive selectivity in GLA- promoted antitumor effect still stays to be investigate.

\section{Mechanisms of the anti-Tumor effects by stimulate cell apoptosis and change cellular fatty acid composition by Omega-6 fatty $\operatorname{acids}(\omega-6 s)$ :}

The $\omega-6 s$ had been proven to exert their anti-tumor proliferation effects via affecting gene and protein spreading, thereby disrupting cell cycle development 
and inducing apoptosis. As an instance, in rat carcinosarcoma cells (LLC-WRC256), GLA caused cytochrome c launch related to modifications in mitochondrial metabolism and improved caspase 3 activity, thereby at the end leading to cell apoptosis [98]. Exogenous GLA remedy was also mentioned to stimulate apoptosis in human and rat glioma cell lines in vitro, while within the in vivo C6 glioma rat model, infusion of GLA elevated the frequency of cell apoptosis, cell death, and regression in tumors [97]. Remedy with CLAs, the derivatives of LA, lead to a G1 arrest in the HT-29 and DU-145 cell lines through increase the protein expression of the cell cycle inhibitor p21 and reducing the expression of cyclins A and D [94, 103]. CLAs have been additionally proven to induce cell apoptosis in numerous tumor cell lines, like Caco-2, HT-29, dRLH-84, SGC-7901, and PC-3, probably through elevate the expression and activity of proapoptotic proteins (e.g. caspase 3, caspase 9, and Fas) while reducing the expression of pro-growth and antiapoptotic proteins (e.g. ErbB3, phosphorylated Akt, BCL-2, cmyc, and Ki-67) [92, 94]. Recommendation, However, further investigations are required to determine whether it is safe to give high-dose of garlic fractions or their components to breast and liver tumor patients as some of the garlic components, such as S-methyl cysteine (SMC), induced cardiomyocyte toxicity in rats when given in a large dose [104].

\section{- Recommendation}

However, further investigations are required to determine whether it is safe to give high-dose of garlic fractions or their components to breast and liver tumor patients as some of the garlic components, such as S-methyl cysteine (SMC), induced cardiomyocyte toxicity in rats when given in a large dose [104].
Funding: No fund was received.

Competing interests: The authors declare that there is no conflict of interest.

\section{References}

1. Bray, F., et al., Global cancer transitions according to the Human Development Index (2008-2030): a population-based study. Lancet Oncol, 2012. 13(8): p. 790-801.

2. Siegel, R.L., K.D. Miller, and A. Jemal, Cancer Statistics, 2017. CA Cancer J Clin, 2017. 67(1): p. 7-30.

3. Siegel, R., et al., Cancer statistics, 2014. CA: a cancer journal for clinicians, 2014. 64(1): p. 9-29.

4. Sultan, M.T., et al., Supplementation of powdered black cumin (Nigella sativa) seeds reduces the risk of hypercholesterolemia. Functional Foods in Health and Disease, 2011. 1(12): p. 516-524.

5. Tapsell, L.C., et al., Health benefits of herbs and spices: the past, the present, the future. Med J Aust, 2006. 185(4 Suppl): p. S4-24.

6. Petrovska, B.B. and S. Cekovska, Extracts from the history and medical properties of garlic. Pharmacogn Rev, 2010. 4(7): p. 106-10.

7. Trio, P.Z., et al., Chemopreventive functions and molecular mechanisms of garlic organosulfur compounds. Food Funct, 2014. 5(5): p. 833-44.

8. Puccinelli, M.T. and S.D. Stan, Dietary Bioactive Diallyl Trisulfide in Cancer Prevention and Treatment. Int $\mathrm{J}$ Mol Sci, 2017. 18(8).

9. Mikaili, P., et al., Therapeutic uses and pharmacological properties of garlic, shallot, and their biologically active 
compounds. Iran J Basic Med Sci, 2013. 16(10): p. 1031-48.

10. Ho, J.N., et al., Anticancer effect of $S$ allyl-L-cysteine via induction of apoptosis in human bladder cancer cells. Oncol Lett, 2018. 15(1): p. 623629.

11. Suleria, H.A.R., et al., Garlic (Allium sativum): diet based therapy of 21st century-a review. Asian Pacific Journal of Tropical Disease, 2015. 5(4): p. 271-278.

12. Nobili, S., et al., Natural compounds for cancer treatment and prevention. Pharmacological research, 2009. 59(6): p. 365-378.

13. Iciek, M., I. Kwiecień, and L. Włodek, Biological properties of garlic and garlic-derived organosulfur compounds. Environmental and molecular mutagenesis, 2009. 50(3): p. 247-265.

14. Butt, M.S., et al., Garlic: nature's protection against physiological threats. Critical reviews in food science and nutrition, 2009. 49(6): p. 538-551.

15. Onyeagba, R., et al., Studies on the antimicrobial effects of garlic (Allium sativum Linn), ginger (Zingiber officinale Roscoe) and lime (Citrus aurantifolia Linn). African Journal of Biotechnology, 2004. 3(10): p. 552554.

16. Pandrangi, A., Cancer chemoprevention by garlic-A review. Hereditary genet, 2015. 4(2): p. 1-7.

17. Linnaeus, C., Species plantarum: a facsimile of the first edition 1753. 1957: Adlard \& Son for the Ray Society.
18. Ejaz, S., L. Woong, and A. Ejaz, EXTRACT OF GARLIC (ALLIUM SATIVUM) IN CANCER CHEMOPREVENTION. 2003.

19. Scozzafava, A., A. Mastrolorenzo, and C. Supuran, Sulfonamides and sulfonylated derivatives as anticancer agents. Current Cancer Drug Targets, 2002. 2(1): p. 55-75.

20. Suleria, H., et al., Aqueous garlic extract; natural remedy to improve haematological, renal and liver status. J Nutr Food Sci, 2013. 4(252): p. 2.

21. Melino, S., R. Sabelli, and M. Paci, Allyl sulfur compounds and cellular detoxification system: effects and perspectives in cancer therapy. Amino Acids, 2011. 41(1): p. 103-12.

22. Rajendran, P., et al., Dietary phytochemicals, HDAC inhibition, and DNA damage/repair defects in cancer cells. Clinical epigenetics, 2011. 3(1): p. 4.

23. Orekhov, A.N., et al., Direct antiatherosclerosis-related effects of garlic. Annals of medicine, 1995. 27(1): p. 63-65.

24. Suleria, H., et al., Aqueous garlic extract attenuates hypercholesterolemic and hyperglycemic perspectives; rabbit experimental modeling. Journal of Medicinal Plants Research, 2013. 7(23): p. 1709-1717.

25. Davis, S.R., An overview of the antifungal properties of allicin and its breakdown products-the possibility of $a$ safe and effective antifungal prophylactic. Mycoses, 2005. 48(2): p. 95-100.

26. Ruddock, P.S., et al., Garlic natural health products exhibit variable constituent levels and antimicrobial activity against Neisseria 
gonorrhoeae, Staphylococcus aureus and Enterococcus faecalis. Phytotherapy Research, 2005. 19(4): p. 327-334.

27. Ariga, T. and T. Seki, Antithrombotic and anticancer effects of garlic-derived sulfur compounds: $A$ review. Biofactors, 2006. 26(2): p. 93-103.

28. Rahman, K. and G.M. Lowe, Garlic and cardiovascular disease: a critical review. The Journal of nutrition, 2006. 136(3): p. 736S-740S.

29. Sultan, M.T., et al., Immunity: plants as effective mediators. Critical reviews in food science and nutrition, 2014. 54(10): p. 1298-1308.

30. Cavallito, C.J. and J.H. Bailey, Allicin, the antibacterial principle of Allium sativum. I. Isolation, physical properties and antibacterial action. Journal of the American Chemical Society, 1944. 66(11): p. 1950-1951.

31. Stoll, A. and E. Seebeck, Chemical investigations on alliin, the specific principle of garlic. Advances in Enzymology and Related Areas of Molecular Biology, Volume 11, 2006: p. $377-400$.

32. Herman-Antosiewicz, A., A. Kawiak, and J. Antosiewicz, An Evidence-based Perspective of Allium Sativum (Garlic) for Cancer Patients. 2011: p. 193-223.

33. Friesen, N., R.M. Fritsch, and F.R. Blattner, Phylogeny and new intrageneric classification of Allium (Alliaceae) based on nuclear ribosomal DNA ITS sequences. Aliso: A Journal of Systematic and Evolutionary Botany, 2006. 22(1): p. 372-395.

34. Fulder, S. and J. Blackwood, Garlic: Nature's Original Remedy. 2000: Inner Traditions/Bear \& Co.
35. Augusti, K. and C. Sheela, Antiperoxide effect of S-allyl cysteine sulfoxide, an insulin secretagogue, in diabetic rats. Experientia, 1996. 52(2): p. 115-119.

36. Makheja, A. and J. Bailey, Antiplatelet constituents of garlic and onion. Agents and actions, 1990. 29(3-4): p. 360-363.

37. Blumenthal, M., A. Goldberg, and J. Brinkman, Herbal Medicine: Expanded German Commission E. American Botanical Council, Austin, TX, 2000: p. 130-133.

38. Agarwal, K.C., Therapeutic actions of garlic constituents. Medicinal research reviews, 1996. 16(1): p. 111-124.

39. YU, T.H. and C.M. WU, Stability of allicin in garlic juice. Journal of Food Science, 1989. 54(4): p. 977-981.

40. Budavari, S., et al., The Merck Index, Merck \& Co. Inc., Rahway, NJ, 1989. 104.

41. Stoll, A. and E. Seebeck, Chemical investigations on alliin, the specific principle of garlic. Adv Enzymol Relat Subj Biochem, 1951. 11: p. 377-400.

42. Block, E., The chemistry of garlic and onions. Scientific american, 1985. 252(3): p. 114-121.

43. Miron, T., et al., The mode of action of allicin: its ready permeability through phospholipid membranes may contribute to its biological activity. Biochimica et Biophysica Acta (BBA)Biomembranes, 2000. 1463(1): p. 2030.

44. Rabinkov, A., et al., The mode of action of allicin: trapping of radicals and interaction with thiol containing proteins. Biochimica et Biophysica 
Acta (BBA)-General Subjects, 1998. 1379(2): p. 233-244.

45. Egen-Schwind, C., R. Eckard, and F. Kemper, Metabolism of garlic constituents in the isolated perfused rat liver. Planta medica, 1992. 58(04): p. 301-305.

46. Kodera, Y., et al., Physical, Chemical, and Biological Properties of $S$ Allylcysteine, an Amino Acid Derived from Garlic. Journal of Agricultural and Food Chemistry, 2002. 50(3): p. 622-632.

47. Islam, M.S., Y. Kusumoto, and M.A. Al-Mamun, Cytotoxicity and Cancer (HeLa) Cell Killing Efficacy of Aqueous Garlic $\quad(<i>$ Allium sativum $</ i>$ ) Extract. Journal of Scientific Research, 2011.3(2).

48. Shin, D.Y., et al., Inhibiting invasion into human bladder carcinoma 5637 cells with diallyl trisulfide by inhibiting matrix metalloproteinase activities and tightening tight junctions. International journal of molecular sciences, 2013. 14(10): p. 19911-19922.

49. Ma, H.-B., et al., Apoptotic pathway induced by diallyl trisulfide in pancreatic cancer cells. World Journal of Gastroenterology: WJG, 2014. 20(1): p. 193.

50. Lan, X., et al., Effects of garlic oil on pancreatic cancer cells. Asian Pacific Journal of Cancer Prevention, 2013. 14(10): p. 5905-5910.

51. $\mathrm{Xu}, \mathrm{Z}$., et al., Preventive effects of garlic oil against the benzene-induced hematotoxicity in mice. Zhonghua lao dong wei sheng zhi ye bing za zhi= Zhonghua laodong weisheng zhiyebing zazhi $=$ Chinese journal of industrial hygiene and occupational diseases, 2014. 32(5): p. 373-375.
52. Na, H.-K., et al., Diallyl trisulfide induces apoptosis in human breast cancer cells through ROS-mediated activation of JNK and AP-1. Biochemical pharmacology, 2012. 84(10): p. 1241-1250.

53. Cha, J.H., et al., Allicin inhibits cell growth and induces apoptosis in U87MG human glioblastoma cells through an ERK-dependent pathway. Oncology reports, 2012. 28(1): p. 4148.

54. Chu, Y.-L., et al., Autophagy therapeutic potential of garlic in human cancer therapy. Journal of traditional and complementary medicine, 2013.3(3): p. 159-162.

55. Chu, Y.-L., et al., Allicin induces p53mediated autophagy in Hep G2 human liver cancer cells. Journal of agricultural and food chemistry, 2012. 60(34): p. 8363-8371.

56. Wang, Y.-B., et al., Diallyl trisulfide induces Bcl-2 and caspase-3dependent apoptosis via downregulation of Akt phosphorylation in human T24 bladder cancer cells. Phytomedicine, 2010. 17(5): p. 363368.

57. Zhang, W., et al., Allicin induces apoptosis in gastric cancer cells through activation of both extrinsic and intrinsic pathways. Oncology reports, 2010. 24(6): p. 1585-1592.

58. Busch, C., et al., Diallylpolysulfides induce growth arrest and apoptosis. International journal of oncology, 2010. 36(3): p. 743-749.

59. Kelkel, M., et al., ROS-independent JNK activation and multisite phosphorylation of Bcl-2 link diallyl tetrasulfide-induced mitotic arrest to apoptosis. Carcinogenesis, 2012. 33(11): p. 2162-2171. 
60. Yu, C.S., et al., Diallyl trisulfide induces apoptosis in human primary colorectal cancer cells. Oncol Rep, 2012. 28(3): p. 949-54.

61. Lee, Y., et al., Anticancer activity of $S$ allylmercapto-L-cysteine on implanted tumor of human gastric cancer cell. Biological and Pharmaceutical Bulletin, 2011. 34(5): p. 677-681.

62. Zhang, W., H. Xiao, and K.L. Parkin, Apoptosis in MCF-7 breast cancer cells induced by $S$ alkenylmercaptocysteine (CySSR) species derived from Allium tissues in combination with sodium selenite. Food and chemical toxicology, 2014. 68: p. 1-10.

63. Dasgupta, P. and S. Sengupta, Role of di-allyl disulfide, a garlic component in $N F-\kappa B$ mediated transient $G 2-M$ phase arrest and apoptosis in human leukemic cell-lines. Nutrition and cancer, 2013. 65(4): p. 611-622.

64. Malki, A., M. El-Saadani, and A.S. Sultan, Garlic constituent diallyl trisulfide induced apoptosis in MCF7 human breast cancer cells. Cancer biology \& therapy, 2009. 8(22): p. 2174-2184.

65. Knowles, L.M. and J.A. Milner, Possible mechanism by which allyl sulfides suppress neoplastic cell proliferation. The Journal of nutrition, 2001. 131(3): p. 1061S-1066S.

66. Sun, H.-J., et al., S-benzyl-cysteinemediated cell cycle arrest and apoptosis involving activation of mitochondrial-dependent caspase cascade through the p53 pathway in human gastric cancer SGC-7901 cells. Asian Pacific Journal of Cancer Prevention, 2013. 14(11): p. 63796384.
67. Herman-Antosiewicz, A., et al., Diallyl trisulfide-induced $G 2 / M$ phase cell cycle arrest in DU145 cells is associated with delayed nuclear translocation of cyclin-dependent kinase 1. Pharmaceutical research, 2010. 27(6): p. 1072-1079.

68. Arunkumar, A., et al., Garlic compound, diallyl disulfide induces cell cycle arrest in prostate cancer cell line $P C$-3. Molecular and cellular biochemistry, 2006. 288(1-2): p. 107113.

69. Wu, P.-P., et al., Diallyl sulfide induces cell cycle arrest and apoptosis in HeLa human cervical cancer cells through the p53, caspase-and mitochondriadependent pathways. International Journal of Oncology, 2011. 38(6): p. 1605-1613.

70. Chu, Y.-L., et al., Allicin induces antihuman liver cancer cells through the p53 gene modulating apoptosis and autophagy. Journal of agricultural and food chemistry, 2013. 61(41): p. 98399848 .

71. Lane, D.P., Cancer. p53, guardian of the genome. Nature, 1992. 358: p. 1516.

72. Yang, A.-K., et al., Herbal interactions with anticancer drugs: mechanistic and clinical considerations. Current medicinal chemistry, 2010. 17(16): p. 1635-1678.

73. Kim, E.J., et al., Thiacremonone, a sulfur compound isolated from garlic, attenuates lipid accumulation partially mediated via AMPK activation in 3T3L1 adipocytes. The Journal of nutritional biochemistry, 2012. 23(12): p. $1552-1558$.

74. Kaneko, T., et al., Inhibition of ENNGinduced pyloric stomach and small 
intestinal carcinogenesis in mice by high temperature-and pressure-treated garlic. Asian Pacific Journal of Cancer Prevention, 2012. 13(5): p. 1983-1988.

75. Stan, S.D. and S.V. Singh, Transcriptional repression and inhibition of nuclear translocation of androgen receptor by diallyl trisulfide in human prostate cancer cells. Clinical Cancer Research, 2009. 15(15): p. 4895-4903.

76. Hahm, E.-R. and S.V. Singh, Diallyl trisulfide inhibits estrogen receptor- $\alpha$ activity in human breast cancer cells. Breast cancer research and treatment, 2014. 144(1): p. 47-57.

77. Altonsy, M.O. and S.C. Andrews, Diallyl disulphide, a beneficial component of garlic oil, causes a redistribution of cell-cycle growth phases, induces apoptosis, and enhances butyrate-induced apoptosis in colorectal adenocarcinoma cells (HT-29). Nutrition and cancer, 2011. 63(7): p. 1104-1113.

78. Li, L., et al., Garlic in clinical practice: an evidence-based overview. Critical reviews in food science and nutrition, 2013. 53(7): p. 670-681.

79. Bat-Chen, W., et al., Allicin purified from fresh garlic cloves induces apoptosis in colon cancer cells via Nrf2. Nutrition and cancer, 2010. 62(7): p. 947-957.

80. Lai, K.C., et al., Diallyl sulfide, diallyl disulfide, and diallyl trisulfide inhibit migration and invasion in human colon cancer colo 205 cells through the inhibition of matrix metalloproteinase2,-7, and-9 expressions. Environmental toxicology, 2013. 28(9): p. 479-488

81. Patil, V., et al., Antimalarial and antileishmanial activities of histone deacetylase inhibitors with triazole- linked cap group. Bioorganic \& medicinal chemistry, 2010. 18(1): p. 415-425.

82. Jo, M., et al., Anti-cancer effect of thiacremonone through down regulation of peroxiredoxin 6 . PloS one, 2014. 9(3): p. e91508.

83. Yedjou, C.G. and P.B. Tchounwou, In vitro assessment of oxidative stress and apoptotic mechanisms of garlic extract in the treatment of acute promyelocytic leukemia. Journal of cancer science \& therapy, 2012. 2012(Suppl 3): p. 006.

84. Sauer, L.A., D.E. Blask, and R.T. Dauchy, Dietary factors and growth and metabolism in experimental tumors. J Nutr Biochem, 2007. 18(10): p. 637-49.

85. Mouradian, M., et al., Key roles for GRB2-associated-binding protein 1, phosphatidylinositol-3-kinase,

cyclooxygenase 2, prostaglandin E2 and transforming growth factor alpha in linoleic acid-induced upregulation of lung and breast cancer cell growth. Prostaglandins, leukotrienes, and essential fatty acids, 2014. 90(4): p. 105-115.

86. Dommels, Y.E., et al., The role of cyclooxygenase in $n-6$ and $n-3$ polyunsaturated fatty acid mediated effects on cell proliferation, PGE(2) synthesis and cytotoxicity in human colorectal carcinoma cell lines. Carcinogenesis, 2003. 24(3): p. 38592.

87. Horrobin, D.F. and V.A. Ziboh, The importance of linoleic acid metabolites in cancer metastasis and in the synthesis and actions of 13-HODE. Adv Exp Med Biol, 1997. 433: p. 2914. 
88. Ewaschuk, J.B., et al., Bioproduction of conjugated linoleic acid by probiotic bacteria occurs in vitro and in vivo in mice. J Nutr, 2006. 136(6): p. 1483-7.

89. Kelley, N.S., N.E. Hubbard, and K.L. Erickson, Conjugated linoleic acid isomers and cancer. J Nutr, 2007. 137(12): p. 2599-607.

90. Chujo, H., et al., Effect of conjugated linoleic acid isomers on growth factorinduced proliferation of human breast cancer cells. Cancer Lett, 2003. 202(1): p. 81-7.

91. De la Torre, A., et al., Conjugated linoleic acid isomers and their conjugated derivatives inhibit growth of human cancer cell lines. Anticancer Res, 2005. 25(6b): p. 3943-9.

92. Beppu, F., et al., Potent inhibitory effect of trans 9 , trans11 isomer of conjugated linoleic acid on the growth of human colon cancer cells. J Nutr Biochem, 2006. 17(12): p. 830-6.

93. Palombo, J.D., et al., The antiproliferative effects of biologically active isomers of conjugated linoleic acid on human colorectal and prostatic cancer cells. Cancer Lett, 2002. 177(2): p. 163-72.

94. Kim, E.J., et al., trans-10,cis-12 conjugated linoleic acid inhibits the G1-S cell cycle progression in DU145 human prostate carcinoma cells. J Med Food, 2006. 9(3): p. 293-9.

95. Ochoa, J.J., et al., Conjugated linoleic acids (CLAs) decrease prostate cancer cell proliferation: different molecular mechanisms for cis-9, trans-11 and trans-10, cis-12 isomers. Carcinogenesis, 2004. 25(7): p. 118591.
96. Liu, J.R., et al., Effect of apoptosis on gastric adenocarcinoma cell line $S G C$ 7901 induced by cis-9, trans-11conjugated linoleic acid. World $\mathrm{J}$ Gastroenterol, 2002. 8(6): p. 999-1004.

97. Leaver, H.A., et al., Antitumour and pro-apoptotic actions of highly unsaturated fatty acids in glioma. Prostaglandins Leukot Essent Fatty Acids, 2002. 66(1): p. 19-29.

98. Colquhoun, A. and R.I. Schumacher, gamma-Linolenic acid and eicosapentaenoic acid induce modifications in mitochondrial metabolism, reactive oxygen species generation, lipid peroxidation and apoptosis in Walker 256 rat carcinosarcoma cells. Biochim Biophys Acta, 2001. 1533(3): p. 20719.

99. Colquhoun, A., Gamma-linolenic acid alters the composition of mitochondrial membrane subfractions, decreases outer mitochondrial membrane binding of hexokinase and alters carnitine palmitoyltransferase I properties in the Walker 256 rat tumour. Biochim Biophys Acta, 2002. 1583(1): p. 74-84.

100. Das, U.N., Tumoricidal and antiangiogenic actions of gamma-linolenic acid and its derivatives. Curr Pharm Biotechnol, 2006. 7(6): p. 457-66.

101. Sagar, P.S. and U.N. Das, Cytotoxic action of cis-unsaturated fatty acids on human cervical carcinoma (HeLa) cells in vitro. Prostaglandins Leukot Essent Fatty Acids, 1995. 53(4): p. 287-99.

102. Vartak, S., et al., Gamma-linolenic acid (GLA) is cytotoxic to $36 B 10$ malignant rat astrocytoma cells but not to 'normal' rat astrocytes. Br J Cancer, 1998. 77(10): p. 1612-20. 
103. Cho, H.J., et al., Trans-10,cis-12, not cis-9,trans-11, conjugated linoleic acid inhibits G1-S progression in HT-29 human colon cancer cells. J Nutr, 2006. 136(4): p. 893-8.

104. El-Magd, M.A., et al., High doses of Smethylcysteine cause hypoxia-induced cardiomyocyte apoptosis accompanied by engulfment of mitochondaria by nucleus. Biomedicine \& Pharmacotherapy, 2017. 94: p. 589597. 